\title{
Природные титаносиликаты Кольской щелочной провинции как прототипы функциональных материалов
}

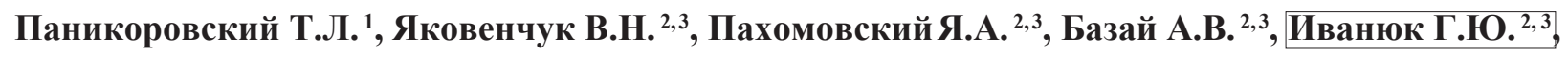
Калашникова Г.О. ${ }^{3}$, Яничева Н.Ю. ${ }^{3}$, Аксёнов С.М. ${ }^{1}$, Николаев А.И. ${ }^{3}$, Чуканов Н.В. ${ }^{4}$, Пеков И.В. ${ }^{5,6}$, Кривовичев C.B. ${ }^{3}$

${ }^{1}$ Лаборатория природоподобных технологий и техносферной безопасности Арктики ФИЦ КНЦ PAH, Anamumbl, taras.panikorovskii@ksc.ru

2 Геологический институт КНЦ РАН, Anamumbl, yakovenchuk@geoksc.apatity.ru, pakhom@geoksc.apatity.ru

${ }^{3}$ Центр наноматериаловедения ФИЦКНЦ РАН, Anamumb, galka27_89@mail.ru, s.krivovichev@ksc.ru

${ }^{4}$ Институт проблем химической физики РАН, Черноголовка,nikchukanov@yandex.ru

${ }^{5}$ Геологический факультет МГУ, Москва, igorpekov@mail.ru

${ }^{6}$ Институт геохимии и аналитической химии (ГЕОХИ) РАН, Москва

Аннотация. Рассмотрены основные структурные особенности прототипов различных функциональных материалов минералов класса титаносиликатов из массивов Кольской щелочной провинции, используемых в качестве сорбентов, молекулярных сит и ионообменников, прекурсоров для дубителей, нелинейнооптических материалов и фотокатализаторов (семейство линтисита-кукисвумита, группа мурманита, каменевит, группа иванюкита, ситинакит, группа зорита, натисит, группа лабунцовита). Ионообменные и сорбционные свойства титаносиликатов обуславливают их применение для очистки жидких радиоактивных отходов с надёжной фиксацией радионуклидов в составе соответствующих матриц и последующем переводом в керамику синрок-типа. Рассмотрены перспективные ионообменники сейдит и тиеттаит - минералы, для которых ещё не получены синтетические аналоги.

Ключевые слова: титаносиликат, кристаллическая структура, микропористый минерал, ионообменник, функциональный материал, щелочной массив, Кольский полуостров.

\section{Titanosilicates of the Kola Alkaline province as a prototypes of various functional materials}

\author{
Panikorovskii T.L. ${ }^{1}$, Yakovenchuk V.N. ${ }^{2,3}$, Pakhomovsky Ya.A. ${ }^{2,3}$, Bazai A.V. ${ }^{2,3}$, Ivanyuk G.Yu. ${ }^{2,3}$, \\ Kalashnikova G.O. ${ }^{3}$, Yanicheva N.Yu. ${ }^{3}$, Aksenov S.M. ${ }^{1}$, Nikolaev A.I. ${ }^{1}$, Chukanov N.V. ${ }^{4}$, Pekov I.V. ${ }^{5}$, \\ Krivovichev S.V.3 \\ ${ }^{1}$ Laboratory of geo-insired technologies and environmental safety of Arctic region FRC KSC RAS, Apatity, \\ taras.panikorovskii@ksc.ru \\ ${ }^{2}$ Geological Institute KSC RAS, Apatity,yakovenchuk@geoksc.apatity.ru, \\ pakhom@geoksc.apatity.ru \\ ${ }^{3}$ Nanomaterials Research Center KSCRAS, Apatity, galka27_89@mail.ru, s.krivovichev@ksc.ru \\ ${ }^{4}$ Institute of Problems of Chemical Physics, Russian Academy of Sciences, Chernogolovka, \\ nikchukanov@yandex.ru \\ ${ }^{5}$ Faculty of Geology, Moscow State University, Moscow, igorpekov@mail.ru \\ ${ }^{6}$ Institute of Geochemistry and Analytical Chemistry GEOCHI RAS, Moscow
}

Abstract. The main structural features of the titanosilicate minerals from intrusions of the Kola alkaline province - prototypes of various functional materials used as sorbents, molecular sieves, ion exchangers, precursors for tanning agents, non-linear optical materials and photocatalysts (lintisite-kukisvumite group, murmanite group, kamenevite, ivanyukite group, sitinakite, zorite group, natisite, labuntsovite group) are considered. The ion-exchange and sorption properties of titanosilicates determine their using for liquid radioactive waste purification with reliable fixation of radionuclides in the corresponding matrices and their subsequent conversion to synroc-type ceramics. The perspective ion-exchangers seidite and tiettaite are considered.

Key words: titanosilicate, crystal structure, microporous mineral, ion exchanger, functional material, alkaline massif, Kola Peninsula. 


\section{Введение}

Находка в 1890 году естествоиспытателем В. Рамзаем в Ловозёрском массиве «нового минерала № 3» - будущего мурманита - положила начало эпохе открытий титаносиликатов в массивах Кольской щелочной провинции. Многие из этих минералов стали прототипами функциональных материалов, которые нашли свое применение в промышленности (Chukanov and Pekov 2005). В настоящее время известны как минимум 69 и 78 представителей этого класса соединений в Хибинском и Ловозёрском щелочных массивах соответственно, в том числе и минералы, открытые авторами данной работы или при их участии (Меньшиков и др. 1992, Yakovenchuk et al. 2009, Pekov et al. 2019, etc.). Природные титаносиликаты, известные в массивах Кольской щелочной провинции, в первую очередь в двух агпаитовых гигантах - Хибинах и Ловозере, относятся к 32 различным структурным типам. Их структуры в наиболее общем виде могут быть описаны как гетеропоэлидрические постройки каркасного или слоистого характера, нередко микропористые (с полостями или каналами до $20 \AA$ в диаметре). Наиболее многочисленны титаносиликаты группы лабунцовита (15 и 18 представителей, здесь и далее - соответственно Хибины и Ловозеро). Также к титаносиликатам среди минералов Хибин и Ловозера относятся 5 и 11 представителей группы лампрофиллита, 5 и 9 - группы мурманита, 4 и 4 - группы ринкита, 1 и 0 - группы бафертисита).

В настоящей работе рассмотрены титаносиликаты с технологически полезными свойствами, как те, чьи аналоги синтезированы и рекомендованы к практическому использованию в качестве различных функциональных материалов (зорит, ситинакит, иванюкит, пенквилксит, натисит и др.), а также те, чьи аналоги ещё не синтезированы (сейдит, тиеттаит).

\section{Каркасные титаносиликаты}

Наиболее разнообразным в структурном отношении является подкласс каркасных титаносиликатов. Наличие двух или трехмерных систем пересекающихся каналов в структурах этих минералов обуславливает их ярко выраженные ионообменные свойства. В настоящее время в материаловедении наиболее интенсивно изучается возможность применения синтетических модификаций зорита (ETS-4), иванюкита (GTS, SIV), каменевита (AM-2, STS), ситинакита (IONSIV-911, TAM-5, STS, CST) (Oleksiinko et al. 2017). Следует также отметить и менее известные минералы группы ловозерита (тисиналит), группы илерита (пятенкоит-(Y)) и группы лабунцовита, имеющие выраженные ионообменные или фотокаталитические свойства (Chukanov and Pekov 2005, Gerasimova 2019).

Группа зорита. Одним из наиболее известных титаносиликатных ионообменников в настоящее время являются синтетические аналоги минералов группы зорита - (Oleksiinko et al. 2017). Зорит $\mathrm{Na}_{6} \mathrm{Ti}(\mathrm{Ti}, \mathrm{Nb})_{4}\left(\mathrm{Si}_{6} \mathrm{O}_{17}\right)_{2}(\mathrm{O}, \mathrm{OH})_{5} \cdot \mathrm{nH}_{2} \mathrm{O}(\mathrm{n}=10-11)$, был открыт сотрудниками Геологического института КНЦ РАН в пегматитовой залежи Юбилейная, г. Карнасурт, Ловозёрский щелочной массив (Мерьков и др. 1973). Впоследствии были открыты аноит и чивруайит - еще два минерала, основу структуры которых составляет титаносиликатный каркас зоритового типа $\mathrm{M}_{5} \mathrm{~T}_{12} \mathrm{O}_{34} \mathrm{X}_{5-8}$ $(\mathrm{M}=\mathrm{Ti}, \mathrm{Nb} ; \mathrm{T}=\mathrm{Si}, \mathrm{S} ; \mathrm{X}=\mathrm{OH}, \mathrm{F}, \mathrm{O})$ (рис. $1 \mathrm{a})$, содержащий каналы вдоль осей b и с. Каналы вдоль оси $\mathrm{b}$ образованы восьмичленными кольцами с сечением диаметром $4.3 \AA$, каналы вдоль оси с ограничены двенадцатичленными кольцами с эллиптическим сечением с основными диаметрами 4.6 и $7.6 \AA$ (Сандомирский, Белов 1979).

Группа иванюкита. Трехмерный фармакосидеритовый каркас (рис. 1 б) состоит из октаэдров $\mathrm{TiO}_{6}$, соединенных по ребрам в кубаноподобные кластеры $\mathrm{Ti}_{4} \mathrm{O}_{16}$. Кластеры, состоящие из четырех октаэдров $\mathrm{TiO}_{6}$, полимеризуются через вершины $\mathrm{SiO}_{4}$ тетраэдров, образуя каркасную постройку с трехмерной системой каналов диаметром 3.5-3.8 $\AA$, заселенных катионами $\left(\mathrm{Na}^{+}, \mathrm{K}^{+}, \mathrm{Ca}^{2+}\right)$ и молекулами воды (Yakovenchuk et al. 2009).

Группа лабунцовита. В основе структуры всех минералов группы лабунцовита (рис. 1 в) находятся кольца $\mathrm{Si}_{4} \mathrm{O}_{12}$, образующие с цепочками из соединяющихся через общие вершины октаэдров $(\mathrm{Ti}, \mathrm{Nb}) \mathrm{O}_{6}$ трехмерный каркас. В структурах большинства минералов группы лабунцовита эти цепочки соединяются между собой еще и дополнительными октаэдрами, как правило, заселёнными 

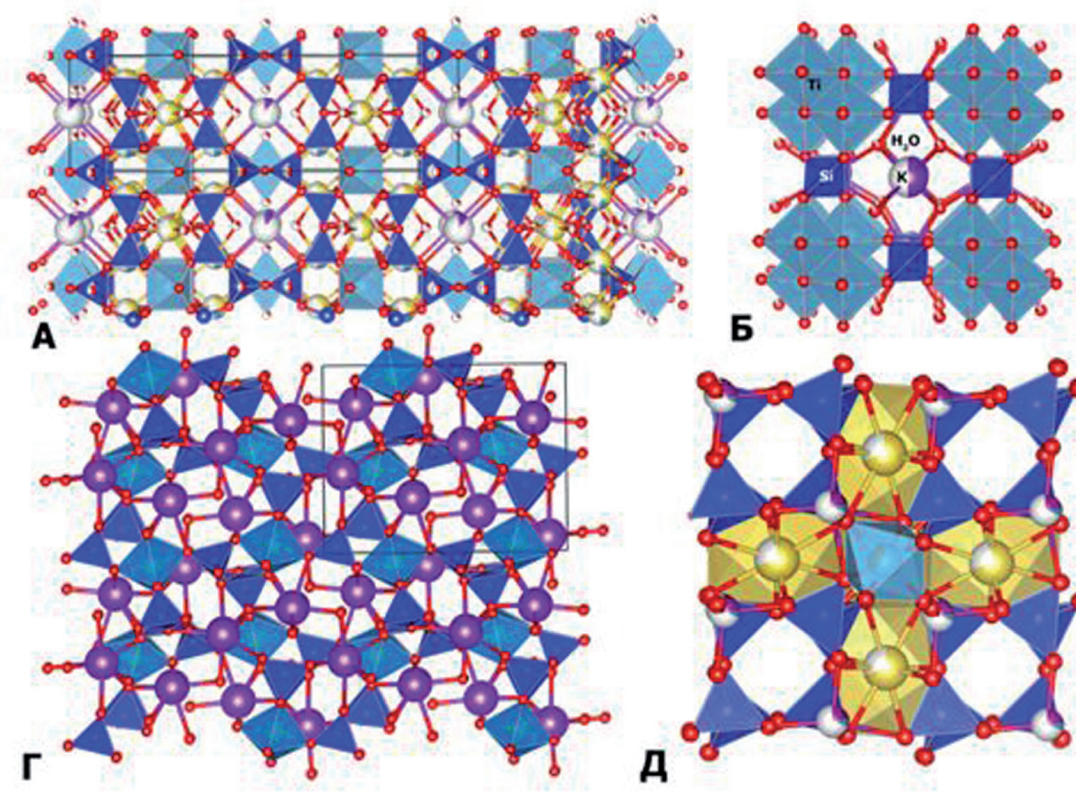

B
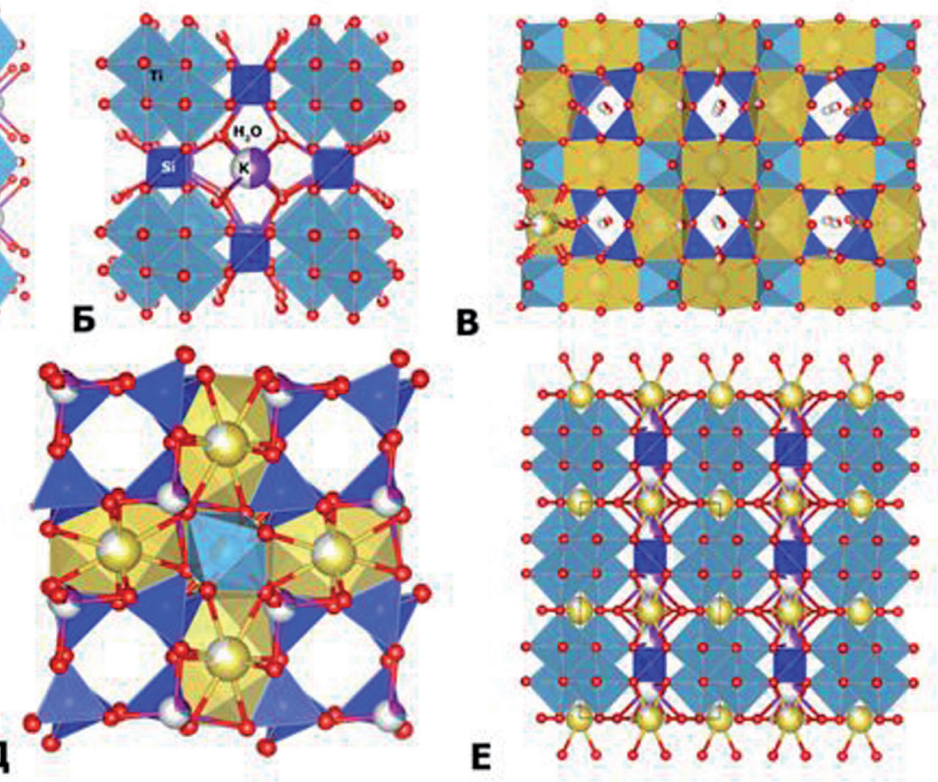

Рис. 1. Кристаллические структуры каркасных титаносиликатов - прототипов функциональных материалов. a - зорит (наши данные), б - иванюкит (Yakovenchuk et al. 2009), в - ненадкевичит (наши данные), г - каменевит (Pekov et al. 2019), д - тисиналит (Ямнова и др. 2003), е - ситинакит (наши данные).

Fig. 1. The crystal structures of framework titanosilicates - prototypes of functional materials. a - zorite (our data), 6 - ivanyukite (Yakovenchuk et al., 2009), в - nenadkevichite (our data), $\Gamma-$ kamenevite (Pekov et al., 2019), д - tisinalite (Yamnova et al., 2003), e - sitinakite (our data).

катионами со средними силовыми характеристиками $\left(\mathrm{Mn}^{2+}, \mathrm{Fe}^{2+}, \mathrm{Mg}^{2+}, \mathrm{Ca}^{2+}\right)$ и имеющими общие рёбра с октаэдрами $(\mathrm{Ti}, \mathrm{Nb}) \mathrm{O}_{6}$. В полостях каркаса находятся полностью или частично заселённые позиции крупных катионов: $\left(\mathrm{Na}^{+}, \mathrm{K}^{+}, \mathrm{Ca}^{2+}, \mathrm{Sr}^{2+}, \mathrm{Ba}^{2+}\right.$ ) (Chukanov et al. 2002).

Каменевит. Аналог умбита (рис. 1 г) с Ті вместо Zr был синтезирован (Zou and Dadachov 2000) задолго до открытия минерального вида каменевита в Хибинском массиве (Pekov et al. 2019). Каркас структуры этого минерала образован волластонитовыми цепочками $\left(\mathrm{Si}_{3} \mathrm{O}_{9}\right)$, направленными вдоль [001], и изолированными друг от друга октаэдрами $\mathrm{TiO}_{6}$. Такая постройка содержит каналы, диаметром $6.8 \AA$, занятые атомами калия и молекулами воды (Chukanov and Pekov 2005).

Группа ловозерита. Эта группа включает три титаносиликатных члена: казаковит, тисиналит и коашвит. Гетерополиэдрический каркас (рис. 1 д) у минералов этой группы и близких к ним соединений можно описать как разорванный. Его основу составляют креслообразные кольца $\mathrm{Si}_{6} \mathrm{O}_{18}$, coединенные по общим вершинам с октаэдрами $\mathrm{MO}_{6}$, где $\mathrm{M}=\mathrm{Zr}, \mathrm{Ti}, \mathrm{Fe}^{3+}, \mathrm{Ca}^{2+}$, которые, в свою очередь связаны по общим граням с частично заселенными $C$-октаэдрами $\left(\square, \mathrm{Mn}^{2+}, \mathrm{Ca}^{2+}\right)$. Каркас пронизан трехмерной системой каналов, занятых ионами $\mathrm{Na}^{+}, \mathrm{Ca}^{2+}$, или молекулами $\mathrm{H}_{2} \mathrm{O}$ (Pekov et al. 2009).

Ситинакит. Синтетический аналог ситинакита $\mathrm{Na}_{2} \mathrm{KTi}_{4} \mathrm{Si}_{2} \mathrm{O}_{13}(\mathrm{OH}) \cdot 4 \mathrm{H}_{2} \mathrm{O}$ - минерала, открытого Ю.П. Меньшиковым и А.П. Хомяковым с соавторами в 1992 г. в Хибинском массиве (Меньшиков и др. 1992), был запатентован американским учёным А. Клирфилдом в 2000 году под названием IONSIV IE-911 (Clearfield et al. 2000). В основе структуры ситинакита (рис. 1 е) лежат тетрамеры Ті-центрированных октаэдров с общим ребром $\left(\mathrm{Ti}_{4} \mathrm{O}_{16}\right)$, соединенные между собой по общим вершинам вдоль [001] и общими вершинами с тетраэдрами $\mathrm{SiO}_{4}$ вдоль направлений [100] и [010] в каркас. Этот гетерополиэдрический каркас содержит двойную систему каналов с максимальным свободным кристаллографическим радиусом $~ 3.5 \AA \AA$; эти каналы заполнены ионами $\mathrm{Na}^{+}, \mathrm{K}^{+}$и молекулами $\mathrm{H}_{2} \mathrm{O}$.

\section{Слоистые и квазислоистые титаносиликаты}

Широким химическим и структурным разнообразием отличаются гетерофиллосиликаты. Недавние работы И.С. Лыковой с соавторами (Лыкова, 2016) показали эффективность минералов 
группы мурманита в отношении сорбции халькофильных элементов: $\mathrm{Ag}, \mathrm{Cu}, \mathrm{Zn}$ и т.д. Синтетические сорбенты со структурами как у минералов семейства линтисита-кукисвумита известны под названием AM-4, искусственный аналог квазислоистого каркасного минерала пенквилксит - как AM-3 и ETS-14. Для натисита, обладающего люминесцентными свойствами, лишь недавно был получен синтетический аналог.

Гетерофиллосиликаты. В основе структур всех этих минералов лежат титаносиликатные (TS) пакеты (рис. 2 a), составленные из октаэдрических $O$ и гетерополиэдрических $H$ слоёв. Между $H O H$ пакетами располагаются межслоевые $I$-блоки, размер которых может значительно варьировать, что делает возможным использование данного типа структур для пилларинга (Ferraris 2008).

Семейство линтисита-кукисвумита. Кристаллические структуры (рис. 2 б) данных соединений образованы двумерными титаносиликатными блоками $\mathrm{Ti}_{2}\left[\mathrm{Si}_{4} \mathrm{O}_{14}\right]^{4}$, толщиной около $10 \AA$, которые объединены в каркасную постройку посредством присоединения «сшивающих» катионов $\mathrm{Na}$, $\mathrm{Li}, \mathrm{Zn}$ или Mn в тетраэдрической или октаэдрической координации (Яковенчук и др. 1991).

Структура натисита (рис. 2в) представляет собой укладку слоев, состоящих из вершинносвязанных пирамид $\mathrm{TiO}_{5}$ и тетраэдров $\mathrm{SiO}_{4}$. Эти слои чередуются со слоями реберно-связанных искаженных октаэдров $\mathrm{NaO}_{6}$ (Egorov-Tismenko et al. 1978).

Для пенквилксита обнаружено два политипа, $2 O$ и $1 M$ (Merlino et al. 1994). Структура первого (рис. 2 г) соответствует синтетическому соединению АМ-3, силикатный мотив которого представляет собой цепочки из зигзагообразных 12-членных колец. Подобную зигзагообразную форму также имеют прилегающий к силикатному $\mathrm{Na}-\mathrm{Ti}$ слой, состоящий из октаэдров $\mathrm{TiO}_{6}$ и полиэдров $\mathrm{NaO}_{7}$.

Среди природных титаносиликатов, для которых ещё не получены синтетические аналоги, наиболее перспективными ионообменнобменниками представляются сейдит и тиеттаит (рис. 2 д, е).
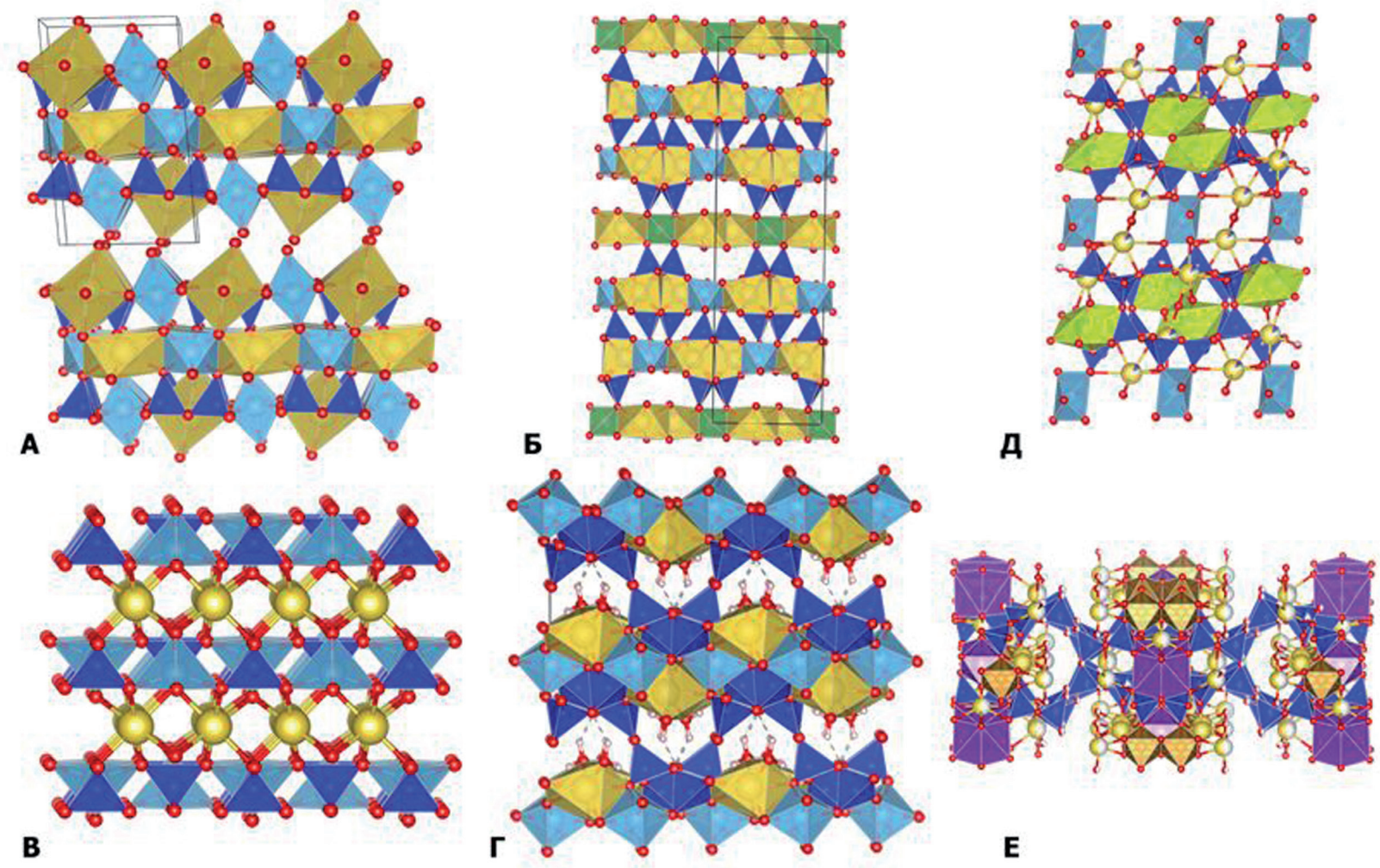

Рис. 2. Кристаллические структуры слоистых и квазислоистых титаносиликатов.

a - мурманит (наши данные), б - линтисит (наши данные), в - натисит (наши данные), г - пенквилксит (Мегlino et al. 1994), д - сейдит-Ce (Ferraris et al. 2003), е - тиеттаит (наши данные.

Fig. 2. The crystal structure of layered and pseudolayered titanosilicates.

a - murmanite (our data), 6 - lintisite (our data), в - natisite (our data), $г$ - penkvilksite (Merlino et al. 1994), д - seidite-(Ce) (Ferraris et al., 2003), e - tiettaite (our data). 
Данные минералы содержат в своих структурах крупные каналы, занятые атомами натрия. Следует отметить, что потенциал исследований минералов класса титаносиликатов остается высоким и неизбежно приведет к открытию новых соединений с полезными свойствами.

Исследования проводились в рамках научной темы ФИЦ КНЦ РАН 0226-2019-0011 (эксперименты по сорбции и синтезу титаносиликатов) и при финансовой поддержке грантов РФФИ 18-29-12039 (изучение кристаллических структур природных титаносиликатов) и 18-29-12007 (кристаллохимический анализ гетерофиллосиликатов).

\section{Литература}

1. Лыкова И.С. Минералы группы эпистолита: посткристаллизационные преобразования и их кристаллохимические механизм: природные системы и модельные эксперименты. Канд. дисс. МГУ. Москва. 2016. 235 c.

2. Меньшиков Ю.П., Соколова Е.В., Егоров-Тисменко Ю.К., Хомяков А.П., Полежаева Л.И. Ситинакит $\mathrm{Na}_{2} \mathrm{KTi}_{4} \mathrm{Si}_{2} \mathrm{O}_{13}(\mathrm{OH}) \cdot 4 \mathrm{H}_{2} \mathrm{O}$ - новый минерал // Записки ВМО. 1992. № 1. С. 94-99.

3. Мерьков А.Н., Буссен И.В., Гойко Е.А., Кульчицкая Е.А., Меньшиков Ю.П., Недорезова А.П. Раит и зорит - новые минералы из Ловозёрских тундр // Записки ВМО. 1973. № 1. С. 54-62.

4. Сандомирский П.А., Белов Н.В. ОД-структура зорита // Кристаллография. 1979. Т. 24. Вып. 6. С. $1198-1210$.

5. Яковенчук В.Н., Пахомовский Я.А., Богданова А.Н. Кукисвумит - новый минерал из щелочных пегматитов Хибинского массива (Кольский п-ов). Минерал. журнал. 1991. Т. 13. № 2. С. 63-67.

6. Я Янова Н.А., Егоров-Тисменко Ю.К., Пеков И.В., Щеголькова Л.В. Кристаллическая структура тисиналита $\mathrm{Na}_{2}(\mathrm{Mn}, \mathrm{Ca})_{1-\mathrm{x}}\left(\mathrm{Ti}, \mathrm{Zr}, \mathrm{Nb}, \mathrm{Fe}^{3+}\right)\left[\mathrm{Si}_{6} \mathrm{O}_{8}(\mathrm{O}, \mathrm{OH})_{10}\right] / /$ Кристаллография. 2003. № 48. С. 602-607.

7. Chukanov N.V., Pekov I.V., Khomyakov A.P. Recommended nomenclature for labuntsovite-group minerals. European Journal of Mineralogy. 2002. V. 14. P. 165-173.

8. Chukanov N.V., Pekov I.V. Heterosilicates with tetrahedral-octahedral frameworks: mineralogical and crystalchemical aspects // Rev. Mineral Geochem. 2005. V. 57. P. 105-143.

9. Clearfield A., Bortun L.N., Bortun A.I. Alkali metal ion exchange by the framework titanium silicate $\mathrm{M}_{2} \mathrm{Ti}_{2} \mathrm{O}_{3} \mathrm{SiO}_{4} \cdot n \mathrm{H}_{2} \mathrm{O}(\mathrm{M}=\mathrm{H}, \mathrm{Na}) .2000$. React Func Polym. V. 43. P. 85-95.

10. Egorov-Tismenko Y.K., Simonov M.A., Belov N.V. The refinement of the crystal structure of the synthetic sodium titanosilicate $\mathrm{Na}_{2}(\mathrm{TiO})\left[\mathrm{SiO}_{4}\right]$. Doklady Akademii Nauk SSSR. 1978. V. 240. P. 78-80.

11. Ferraris G., Belluso E., Gula A., Soboleva S.V., Khomyakov A.P. Canadian Mineralogist. 2003. V. 41. P. $1183-1192$.

12. Ferraris G. Heterophyllosilicates, a Potential Source of Nanolayers for Materials Science. In: Krivovichev S.V. (eds) Minerals as Advanced Materials I. Springer, Berlin. Heidelberg. 2008.

13. Gerasimova L.G., Nikolaev A.I., Shchukina E.S., Maslova M.V., Kalashnikova G.O., Samburov G.O., Ivanyuk G. Yu. Hydrochloric acid processing of titanite ore to produce a synthetic analogue of korobitsynite // Minerals. 2019. V. 9. 315 p.

14. MacDonald A.M. and G.Y. Chao Haineaultite, a new hydrated sodium calcium titanosilicate from Mont SaintHilaire, Quebec: description, structure determination and genetic implications. Canadian Mineralogist. 2004. V. 42. P. 769-780.

15. Men'shikov Y.P., Krivovichev S.V., Pakhomovsky Y.A., Yakovenchuk V.N., Ivanyuk G.Y., Mikhailova J.A., Armbruster T., and Selivanova E.A. Chivruaiite, $\mathrm{Ca}_{4}(\mathrm{Ti}, \mathrm{Nb})_{5}\left[\left(\mathrm{Si}_{6} \mathrm{O}_{17}\right)_{2}(\mathrm{OH}, \mathrm{O})_{5}\right]^{*} 13-14 \mathrm{H}_{2} \mathrm{O}$, a new mineral from hydrothermal veins of Khibiny and Lovozero alkaline massifs // American Mineralogist. 2006. V. 91. P. 922-928.

16. Merlino S., Pasero M., Artioli G., Khomyakov A.P. Penkvilksite, a new silicate structure: OD character, X-ray single crystal (1M) and powder Rietveld (2O) refinements of two MDO polytypes. American Mineralogist. 1994. V. 79. P. 1185-1193.

17. Merlino S, Pasero M, Artioli G, Khomyakov A.P. Penkvilksite, a new kind of silicate structure: OD character, X-ray single-crystal (1M), and powder Rietveld (2O) refinements of two MDO polytypes, American Mineralogist. 1994. V. 79. P. 1185-1193.

18. Oleksiienko O., Wolkersdorfer C., Sillanpaa M., Titanosilicates in cation adsorption and cation exchange-a review. Chem. Eng. J. 2017. V. 317. P. 570-585.

19. Pekov I.V., Krivovichev S.V., Zolotarev A.A., Yakovenchuk V.N., Armbruster T. \& Pakhomovsky Y.A. Crystal chemistry and nomenclature of the lovozerite group. European Journal of Mineralogy. 2009. V. 21. P. 1061-1071.

20. Pekov I.V., Zubkova N. V., Yapaskurt V.O., Belakovskiy D.I., Lykova I.S., Britvin S. N., Turchkova A.G., Pushcharovsky D.Y. Kamenevite, $\mathrm{K}_{2} \mathrm{TiSi}_{3} \mathrm{O}_{9} \cdot \mathrm{H}_{2} \mathrm{O}$, a new mineral with microporous titanosilicate framework from the Khibiny alkaline complex, Kola peninsula, Russia. European Journal of Mineralogy. 2019. N. 31(3). P. 557-564.

21. Yakovenchuk V.N., Nikolaev A.P., Selivanova E.A., Pakhomovsky Ya.A. Korchak J.A., Spiridonova D.V., Zalkind O.A. Krivovichev S.V. Ivanyukite-Na-T, ivanyukite-Na-C, ivanyukite-K, and ivanyukite-Cu: New microporous titanosilicates from the Khibiny massif (Kola Peninsula, Russia) and crystal structure of ivanyukiteNa-T // American Mineralogist. 2009. V. 94. P. 1450-1458.

22. Zou X.D. and Dadachov M.S. $\mathrm{K}_{2} \mathrm{TiSi}_{3} \mathrm{O}_{9} \cdot \mathrm{H}_{2} \mathrm{O}$, Acta Crystallogr. C: Cryst. Struct. Commun. 2000. V. 566. P. $738-739$. 